laser provides far better results, particularly in children. In view of its clear advantages over the other lasers, whose rate of energy delivery does not match the predicted physical behaviour of the blood vessels, we suggest that the pulsed dye laser should be offered as the first line treatment for portwine stains whenever possible.

M J C VAN GEMERT Professor of Laser Medicine

Laser Centre, Academic Medical Centre, Amsterdam 1105AZ,

The Netherlands

J A S CARRUTH Consultant Otolaryngologist

ENT Department,

Royal South Hants Hospital,

Southampton SO9 4PE

P G SHAKESPEARE Director

Laing Laboratory, Odstock Hospital, Salisbury SP2 8BJ
3 Carruth JAS, van Gemert MJC, Shakespeare PG. The argon laser in the treatment of the port-wine tain birthmark. In: Tan OT, ed. Management and treatment of benign cutaneous vascular lesions. Philadelphia: Lea and Febiger, 1992;53-67.

4 Apfelberg DB, Smith T, White J. Preliminary study of the vascular dynamics of the portwine haemangioma with therapeutic implications of Argon laser treatment. Plastic and Reconstructive Surgery 1989;83:820-7.

5 Masser MR, Sammut DP, Jones SG, Saxby PJ. Argon laser therapy of portwine stains-prediction of the effect by transcutaneous microscopy. Lasers in Medical Science 1989;4:237-40.

6 Tan OT, Carney JM, Margolis R, Seki Y, Boll J, Anderson RR, et al. Histologic responses of portwine stains treated by argon, carbon dioxide, and tunable dye lasers: a preliminary report. Arch Dermatol 1986;122:1016-22.

European Community Haemangioma Working Party. Lasers in medical science (in press).

8 Anderson RR, Parish JA. Microvasculature can be selectively damaged using dye lasers: a basic theory and experimental evidence in human skin. Lasers Surg Med 1981;1:263-76.

van Gemert MJC, Pickering JW, Welch AJ. Modelling laser treatment of port-wine stains. In: Tan OT, ed. Management and treatment of benign cutaneous vascular lesions. Philadelphia: Lea and Febiger, 1992:24-47.

Tan OT, Morrison P, Kurban AK. $585 \mathrm{~nm}$ for the treatment of portwine stains. Plast Reconstr Surg 1990;86:1112-7.

11 Pickering JW, Walker EP, Butler PH, van Halesijn CN. Copper vapour laser treatment of portwine stains and other vascular malformations. Br f Plast Surg 1990;43:273-82.

12 Scheiber A, Wheeland RG. Argon pumped tunable dye laser therapy for facial portwine stain hemangiomas in adults-a new technique using small spot size and minimal power. $f$ Denmatol Surg Oncol 1989;15:277-82.

13 Laffitte F, Mordon S, Chavoin JP, Bonafe JL, Rouge D, Costagliola M. The frequency-doubled Nd-YAG laser with automated scanning in the treatment of portwine stains: a preliminary report. Lasers in Medical Science 1992;7:341-9.

14 Neumann RA, Knobler RM, Leonhartsberger H, Bohler-Sommeregger K, Gebhart W. Histochemical evaluation of the coagulation depth after argon laser impart on a port-wine stain. Lasers Surg Med 1991:11:606-15.

15 Tan OT, Sherwood K, Gilchrest BA. Treatment of children with portwine stains using the flashlamp-pulsed tuneable dye laser. N Engl F Med 1989;320:416-21.

16 Tan OT. Pulsed dye laser treatment of adult port-wine stains. In: Tan OT, ed. Management and treatment of benign cutaneous vascular lesions. Philadelphia: Lea and Febiger, 1992;83-99.

\title{
Treating persistent glue ear in children
}

\author{
More patience, less surgery
}

Glue ear, or more precisely otitis media with effusion, is the major cause of hearing problems in children. How should it be managed? Currently, about one child in 200 in England is treated surgically for the condition each year, making it the commonest reason for elective surgery in children. On the basis of a literature review the most recent Effective Health Care bulletin questions such frequent intervention. ${ }^{12}$

Its authors recommend a period of "watchful waiting" before proceeding to surgery. They also recommend large trials to examine the effectiveness of a range of interventions, which should look at broader outcome measures than just hearing loss. They base their recommendations on an analysis of 19 randomised controlled trials that examined the effectiveness of surgical interventions for glue ear. Most attention was given to the three trials that used hearing level as an outcome measure.

The authors recognise the many methodological problems in studying disabilities that may result from hearing impairment. Social functioning, speech, language, learning, and behaviour may all be affected. They quote the comprehensive review by Haggard and Hughes, which states that glue ear probably causes considerable disability only if it results in persistent impaired hearing starting at an early age. ${ }^{3}$ In the Dunedin study children with persistent effusions from a young age had problems with learning, language, and development at least until they were aged 7 to $9 .{ }^{4}$ Whether these problems are temporary or not is still unclear. ${ }^{5}$ Other crucial questions-for example, does surgical intervention prevent problems at school and of language-are still unanswered.

The bulletin suggests that grommets and adenoidectomy, either alone or in combination, reduce mean hearing impairment by less than $12 \mathrm{~dB}$ at six months, and that this improvement falls with time. Myringotomy and tonsillectomy, either alone or in combination, are ineffective. Despite these unpromising results and the fact that most episodes of glue ear are of short duration and resolve spontaneously (50\% within three months; $95 \%$ within a year) the "epidemic" of surgery for glue ear continues.

To reduce surgical activity for glue ear the authors recommend a period of continued observation and testing in children with bilateral hearing impairment of $25 \mathrm{~dB}$ or more. This guidance should exclude from surgery most children whose effusions will resolve quickly. Children on waiting lists should be reassessed to ensure that intervention is still required. This presupposes the existence of good audiological services.

The bulletin lists the side effects of grommets: tympanosclerosis, increased incidence of chronic perforation, and possibly cholesteatoma. A cohort of children, originally seen aged 2 to 4 with severe effusions and mostly treated with grommets, had structural damage of the eardrum $(87 \%$ of cases), abnormal tympanograms (45\%), and a mean hearing loss of $13 \mathrm{~dB}$ when followed up at the age of $8 .^{6}$ Whether such substantial damage resulted from surgery or the disease itself is not known: what is certain is that a very restrictive policy regarding the insertion of grommets is necessary. ${ }^{6}$ Unlike grommets, adenoidectomy seems to modify the underlying pathophysiology of chronic otitis media with effusion ${ }^{7}-$ making it our initial surgical procedure of choice in cases of severe, persistent effusion. Whether antibiotics could be a satisfactory alternative to surgery in the long term is unclear; some studies show possible short term benefits. ${ }^{89}$

Ideas about the pathophysiology of glue ear are changing, with attention shifting from obstruction of the eustachian tube to dysfunction of the tube and immunological mechanisms. In some-perhaps most-cases effusion may be a normal reaction to an upper respiratory tract infection. Surgical intervention would therefore be unjustified.

Upper respiratory tract infections, especially acute otitis media, are the most important determinants for the development of an effusion. Acute otitis media and otitis media with effusion are associated-they may be different aspects of the same condition. Prognostic factors, such as age less than 2 and 
recurrent acute otitis media, may help to identify a subgroup of children prone to effusions who require closer follow up. ${ }^{10}$

General practitioners are well placed to diagnose effusion and carry out the necessary surveillance. Microtympanometry, a sensitive method of diagnosing effusions of the middle ear, could help them in this. ${ }^{11}$ Doctors should be able to reassure the parents of most affected children that the effusions will resolve without any further action or adverse sequelae.

RUUT A DE MELKER

Chairman,

Department of General Practice,

University of Utrecht,

3511 ZC Utrecht, Netherlands
The treatment of persistent glue ear in children. Effective Health Care 1992; No 4

Robinson R. Less surgery for glue ear, says bulletin. $B M \mathcal{F} 1992 ; 305 ; 1454-5$.

Haggard $M$, Hughes $\mathrm{G}$. Screening children's hearing. A review of the literature and the implications of otitis media. London: HMSO, 1991.

Chalmers DC, Stewart I, Silva P, Mulvena A. Otitis media with effusion in children-the Dunedin sindy. London: MacKeith Press, 1989.

Paradise J. Otitis media during early life: how hazardous to development? Pediarrics 1981,68: 869-73.

6 Schilder AGM, Zielhuis GA, van den Broek P. De lange termign effecten van otitis media met effusie. Nigmegen: Katholieke Universiteit, Nimegen, 1991.

7 Gates GA, Cooper JC, Avery A, Prihoda TJ. Chronic secretory otitis media: effects of surgical management. Ann Otol Rhinol Laryngol 1989;89(suppl 138): 1-32.

8 Mandel EM, Rockette HE, Bluestone ChD, Paradise JL, Nozza RJ. Efficacy of amoxycillin with or without decongestant-antihistamine for otitis media with effusion in children. $N$ Engl $9 \mathrm{Med}$ 1987;316:432-7.

9 Thomsen J, Sederberg-Olsen J, Balle V, Vejlsgaard R, Stangerup SE, Bundesson G. Antibiotic treatment of children with secretory otitis media. Arch Otolaryngol Head Neck Surg 1989;115: 447-51.

10 Appelman CLM, Claessen JQPJ. Recurrent acute otitis media [dissertation]. Utrecht: University of Utrecht, 1992.

11 De Melker RA. Diagnostic value of microtympanometry in primary care. BMf 1992;304:96-7.

\section{Academic medicine: plenty of room at the top}

\section{Too many barriers to getting well trained}

Contrary to conventional wisdom, there is a shortage of doctors to fill senior research posts. "High quality clinical researchers are like gold dust," said Diana Dunstan of the Medical Research Council at a meeting on opportunities in clinical research held at the Royal College of Physicians just before Christmas. The council has difficulty filling its senior training fellowships and professorships, and so, other speakers confirmed, do the major medical charities. "If you want a career in research and you are able then you have absolutely no need to worry," Peter Lachmann, president of the Royal College of Pathologists, told the young doctors at the conference. "Clinical research," he said, "is a shortage specialty." A great many young doctors do enter research, but few are reaching the stage where they are qualified for the senior jobs. What is the block?

The first problem is that many young doctors do not get an adequate training. Speakers like Sir David Weatherall from Oxford and Keith Peters from Cambridge all agreed that a proper training means at least three years doing nothing but research. Furthermore, the training must be in a good centre and must be well supervised. In effect this means doing a PhD rather than an $M D$, and the message from the conference was that an MD is a devalued degree. Yet the reality for most doctors is that their research time is undermined by clinical commitments ("Research can wait but patients can't") and training and supervision are poor. "Too much time is spent on ill considered, ill conceived research," said Mike Peckham, director of research and development in the NHS.

Another problem is the need to get accredited. The several presidents of colleges present at the meeting kept insisting that "accreditation is dead" and not a problem: there is plenty of flexibility in the system, they said. Yet it didn't feel that way to the young doctors. "We are made to do things that are a waste of time in order to get accredited," said one. "The colleges want their pound of flesh," said another. The only spontaneous applause during the day was for Sir Christopher Booth, who said: "The colleges ought to realise that accreditation is for NHS consultants working alone and that a quite different form of accreditation is needed for research academics working in teams."

The deeper problem for doctors going into research is the antiscience culture that is more important in medicine than many would care to admit. For example, Professor Peckham quoted a director of public health who said that people did not ask about research evidence even when making difficult decisions. Doctors who want to devote much of their time to research are undervalued. Inevitably they have more restricted clinical skills than those who practise full time. Particularly in the macho world of surgery, the researchers' clinical limitations may raise eyebrows while their abilities in molecular biology are more likely to be seen as a threat than an achievement. (An irony of the conference was that not one shred of evidence was produced for the central assertion that three years' full time training in research was essential.)

Money is another factor diverting doctors from a career in research, although it was not discussed much at the conference. The sad truth is that doctors who spend careers in research may forgo huge incomes from private practice. This is especially true in surgery and cardiology, two of the specialties that have the greatest difficulty in producing adequately trained academics.

The group who face the most difficulty getting adequately trained are women doctors, and they made their voices heard at the conference despite the organisers admitting with startling candour that they had not anticipated that this issue would arise. The women wanted more opportunities for part time training in research, but the male establishment was doubtful-arguing that "triple accreditation" as a clinician, scientist, and mother was too much. The women pointed out that many of the most able graduates were women and that it was shortsighted of the establishment simultaneously to be moaning about the lack of people at the top and disenfranchising half of medical graduates. Indeed, the one thing that spoilt this lively conference was the patronising references to women, district general hospitals, and general practice.

The conference illustrated why so few doctors manage to reach a position where they can apply for the senior fellowships and professorships, but answers were less forthcoming. The Medical Research Council is about to review its training structure, and the colleges clearly need to clarify the message on accreditation. But real developments may demand financial and cultural changes which may be difficult to achieve. My final message is to repeat that I think that Britain needs an organisation of researchers under 40 like those that exist in the United States and Australia. ${ }^{12}$ Such an organisation can campaign for better conditions for researchers, provide mutual support and advice, and talk up the importance of medical research with the public, schoolchildren, the government-and other doctors.

Editor, $B M \mathcal{F}$

RICHARD SMITH

Smith R. Science in Australia: alive, well, kicking, and growing. BMf 1991;302:840-2. 2 Smith R. Strangling the future. BMf 1991;302:977-8. 